\title{
Habitat selection in the lesser cuckoo, an avian brood parasite breeding on Jeju Island, Korea
}

\author{
Seongho Yun ${ }^{1,2}$, Jin-Won Lee ${ }^{1,2^{*}}$ and Jeong-Chil Yoo ${ }^{1,2}$
}

\begin{abstract}
Background: Determining patterns of habitat use is key to understanding of animal ecology. Approximately $1 \%$ of bird species use brood parasitism for their breeding strategy, in which they exploit other species' (hosts) parental care by laying eggs in their nests. Brood parasitism may complicate the habitat requirement of brood parasites because they need habitats that support both their host and their own conditions for breeding. Brood parasitism, through changes in reproductive roles of sex or individual, may further diversify habitat use patterns among individuals. However, patterns of habitat use in avian brood parasites have rarely been characterized. In this study, we categorized the habitat preference of a population of brood parasitic lesser cuckoos (Cuculus poliocephalus) breeding on Jeju Island, Korea. By using compositional analyses together with radio-tracking and land cover data, we determined patterns of habitat use and their sexual and diurnal differences.
\end{abstract}

Results: We found that the lesser cuckoo had a relatively large home range and its overall habitat composition (the second-order selection) was similar to those of the study area; open areas such as the field and grassland habitats accounted for $80 \%$ of the home range. Nonetheless, their habitat, comprised of 2.54 different habitats per hectare, could be characterized as a mosaic. We also found sexual differences in habitat composition and selection in the core-use area of home ranges (third-order selection). In particular, the forest habitat was preferentially utilized by females, while underutilized by males. However, there was no diurnal change in the pattern of habitat use. Both sexes preferred field habitats at the second-order selection. At the third-order selection, males preferred field habitats followed by grasslands and females preferred grasslands followed by forest habitats.

Conclusions: We suggest that the field and grassland habitats represent the two most important areas for the lesser cuckoo on Jeju Island. Nevertheless, this study shows that habitat preference may differ between sexes, likely due to differences in sex roles, sex-based energy demands, and potential sexual conflict.

Keywords: Core-use area, Habitat composition, Habitat preference, Home range, Radio-tracking, Sexual difference

\footnotetext{
* Correspondence: jwlee99@khu.ac.kr

${ }^{1}$ Korea Institute of Ornithology, Kyung Hee University, Seoul 02447, Republic

of Korea

${ }^{2}$ Department of Biology, Kyung Hee University, Seoul 02447, Republic of

Korea
}

(c) The Author(s). 2020 Open Access This article is licensed under a Creative Commons Attribution 4.0 International License, which permits use, sharing, adaptation, distribution and reproduction in any medium or format, as long as you give appropriate credit to the original author(s) and the source, provide a link to the Creative Commons licence, and indicate if changes were made. The images or other third party material in this article are included in the article's Creative Commons licence, unless indicated otherwise in a credit line to the material. If material is not included in the article's Creative Commons licence and your intended use is not permitted by statutory regulation or exceeds the permitted use, you will need to obtain permission directly from the copyright holder. To view a copy of this licence, visit http://creativecommons.org/licenses/by/4.0/. 


\section{Background}

The habitat of an animal refers to the natural environment that contains essential resources for survival and reproduction, such as food, shelter, and nest sites (Brown 1988; Ersts and Rosenbaum 2003). The abundance and distribution of these resources may differ according to the type of habitat. Different species of animals may need different types of resources, potentially resulting in divergence among species in habitat preference (Cody 1985; Pulliam and Danielson 1991). Habitat preference may also differ among conspecific individuals owing to differences in food availability and potential competitive ability based on sex or age (Bon and Campan 1996; Darden and Croft 2008; Martin and da Silva 2004; Mysterud 2000). Therefore, determining the patterns of habitat use is key to assessing critical resources for animals and managing their habitats for conservation purposes.
Avian brood parasites rely exclusively on other species (i.e., hosts) to breed, by laying eggs in their nests (Hauber and Dearborn 2003). Due to this unique breeding strategy, their habitat selection may differ from that of host birds, which require sufficient food and available nest sites for successful breeding. Optimal breeding habitat for brood parasites should include sufficient hosts and food resources (Croston and Hauber 2010; Payne 2005). Freedom from parental care and sex role differences may further differentiate breeding habitat preference between sexes in avian brood parasites. In Cuculus cuckoos, for example, males provide sperms only for successful breeding; therefore, they should mate with as many females as possible to maximize their fitness (Hauber and Dearborn 2003). Instead of frequent mating, females are expected to secure sufficient resources for egg production and to search for and monitor host nests to lay eggs, within the optimal time period to maximize their fitness (Hauber and Dearborn 2003;

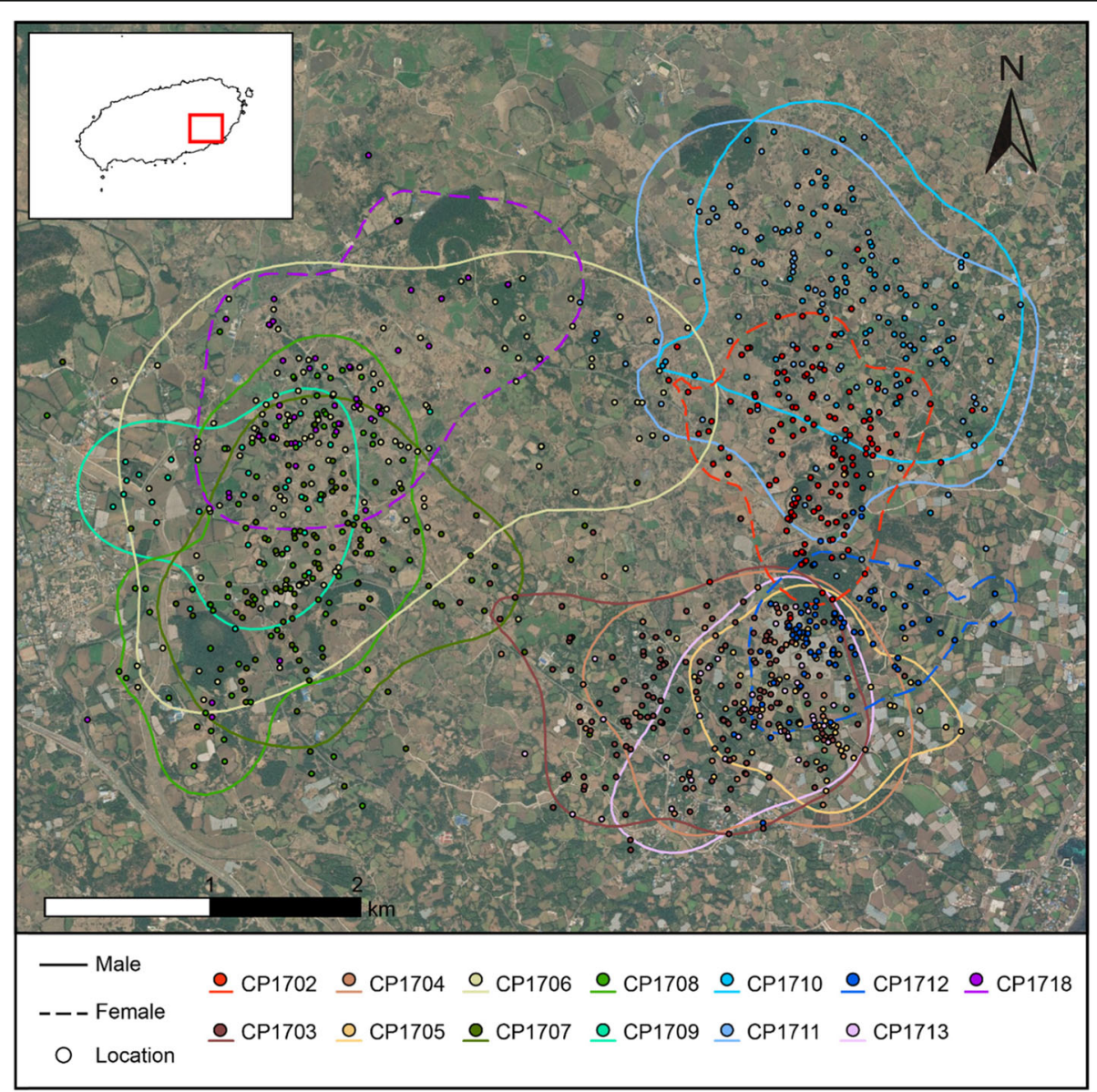

Fig. 1 A map showing the habitat characteristics of study area and the example of individual home ranges with their observation locations (individuals tracked in 2017). Different colors of dots and lines (solid or dotted) represent observation locations of different individuals and their home range areas, respectively 
Ward 1996). These sex-related differences may generate different habitat preferences between male and female cuckoos. In addition, potential sexual conflict over optimal mating rates and resultant sexual harassment by males may force females to escape from males, resulting in fine-scale habitat segregation between sexes (Darden and Croft 2008; Lee et al. 2019; Martin and da Silva 2004). However, few studies have attempted to determine the pattern of habitat use in avian brood parasites.

In this study, we investigated the habitat selection of radio-tracked lesser cuckoos (Cuculus poliocephalus) a small-sized (ca. $60 \mathrm{~g}$ ) brood parasite. This species is a summer visitor in Korea, primarily parasitizing the Japanese bush warbler (Horornis diphone) between May and July (Lee 2014; Yun et al. 2019; Yoo et al. 2020). Although this species has been designated as a Korean Natural Monument (No. 447) and protected since 2005, their pattern of habitat use has rarely been quantified. Specifically, we first quantified the habitat composition of the entire study area inhabited by the lesser cuckoo and estimated their home range and core-use area. From these data, we then analyzed habitat preference with a focus on sexual and diurnal differences.

\section{Methods}

\section{Fieldwork and radio-tracking}

Radio-tracking of lesser cuckoos was conducted on the eastern part of Jeju Island $\left(33^{\circ} 28^{\prime} \mathrm{N}, 126^{\circ} 49^{\prime} \mathrm{E}\right.$, Fig. 1) in the Republic of Korea from May to June in 2016 and June to July in 2017. We captured cuckoos using mist nets with a decoy and playback of female calls. Upon capture, individuals were first banded with a metal ring, measured (e.g., primary wing length and body mass), and photographed. We then attached a radiotransmitter, weighing $0.64 \mathrm{~g}$, on a rachis from their middle rectrices, using instant adhesive, and subsequently released the bird at the site where they were captured. The attached transmitter is expected to safely detach during subsequent molting (Godet et al. 2015; Sykes et al. 1990). We located and tracked individuals using three-element Yagi antennae and receivers (Sika, Biotrack, UK; IC-R20, Icom, Japan). Tracking was performed every day during the study period from 04:00 to 20:00, except for midday (i.e., 12:00-15:00) or rainy periods, when activity is expected to be low (Yoo et al. 2020). The tracking process proceeded as follows: we first searched for the target signal in a slow moving car; once detected, the signal was located and tracked on foot and by car as necessary. The target signals location was recorded every $10 \mathrm{~min}$. All areas and individuals were systematically assessed. When target signals showed no movement for three consecutive days, we regarded it as accidental transmitter removal or predation occurred and stopped tracking.

\section{Defining the study area and home range}

Study area boundaries are often defined arbitrarily, which can lead to inaccuracies in determining habitat composition (Bozek et al. 2007; Johnson 1980). To minimize such inaccuracies, the study area and its boundary were determined based on $100 \%$ minimum convex polygons (MCP) with a $200 \mathrm{~m}$ buffer, using all location data from all radio-tracked lesser cuckoos (Bozek et al. 2007; Mohr 1947).

We used a fixed kernel density estimator to estimate the home range of the lesser cuckoo in ArcGIS 10.1(ESRI, USA). Kernel home ranges are a non-parametric probabilistic estimate of home range, based on the distribution and concentration of locations, covering $95 \%$ of all location points for each individual (Dickson and Beier 2002) (Fig. 1). Home ranges were estimated for individuals which were monitored for at least 4 days and had more than 30 recorded locations (Seaman et al. 1999). The selection criteria resulted in home ranges for 16 males and five females, for use in subsequent analyses of habitat selection. The effect of sex, year, wing length, and the number of location fixes on home range size was assessed using a linear regression model, for which home range size was log-transformed to satisfy normality. The maximum model included all variables, together with their two-way interaction, while the minimal adequate model was reached by the sequential removal of non-significant terms (Freeman and Jackson 1990; Crawley 2012).

\section{Classifying habitat types}

We classified habitats into five different types according to typical and homogeneous vegetation types: field, grassland, forest, orchard, and anthropogenic area. Field habitat was characterized by agricultural fields for crops such as radish, potato, and fodder (e.g., Gramineae). Shrubs and trees were often found along the edge of field habitat. Grassland habitat represented a natural environment where herbaceous plants dominantly occur with shrubs and trees scattered throughout. Forest habitat consisted of a mixture of broadleaf and coniferous trees with dense canopies (e.g., Pinus, Cryptomeria, and Cinnamomum spp.). Orchard habitats were represented by cultivated citrus trees (Citrus spp.) and were often sprayed with pesticides. Finally, the anthropogenic habitats included areas where human disturbance were severe and frequent, such as towns, wastelands, and greenhouses. The typical nest site of cuckoos' major host species, the Japanese bush warbler utilized in our study area, was characterized by trees and shrubs such as the Japanese holly (Ilex crenata) and the arrow bamboo (Pseudosasa japonica). These potential nest sites were mostly distributed along the boundaries of the various habitats described above (Hamao 2014; Hamao and Hayama 2015). 


\section{Quantifying habitat composition}

To investigate the habitat selection of lesser cuckoos, we first determined the habitat composition of the entire study area by calculating the proportion each habitat occupied within the study area. The habitat occupancy provided reference data for habitat availability in the study area, which allowed for the calculation of habitat composition for the home range of individuals. The habitat composition of the whole study area and individual home range were determined using a land cover digital map with $1 \mathrm{~m} \times 1 \mathrm{~m}$ resolution provided by Environmental Geographic Information Service (EGIS, last updated in 2016; https://egis.me.go.kr/). For individual home ranges, we clipped the area corresponding to the respective home range from this map and calculated habitat composition in ArcGIS. Habitat composition was calculated as the relative proportion of each habitat type described above, the sum of which was $100 \%$.

Animals may not use the entire home range evenly but may have certain preferred sites which they use more regularly (Rettie and McLoughlin 1999). Thus, habitat selection estimated from the habitat composition of the whole home range may differ from actual habitat preference characteristic of each lesser cuckoo. To alleviate this problem, we also calculated the habitat composition of a $200-\mathrm{m}$ radius circle at each location point. From these data, we calculated the average proportion of each habitat type in each $200 \mathrm{~m}$ radius circles for each individual, which we could use (hereafter defined as "core-use area") to weight the frequently used areas (Dickson and Beier 2002; Rettie and McLoughlin 1999).

\section{Assessing habitat preference}

Habitat selection was assessed by comparing the composition of used and available habitats at two spatial scales: home range $v s$. whole study area (i.e., "second-order habitat selection") and core-use area vs. home range (i.e., "third-order habitat selection") (Aebischer et al. 1993). Using the rrcov package (Todorov and Filzmoser 2009) in R 3.5.0 (R Core Team 2017), we employed a multivariate analysis of variance (MANOVA), with Wilks' lambda statistic $(\Lambda)$, to determine the statistical significance of differences in habitat composition between used and available habitats for all individuals. We also conducted pairwise preference comparisons between habitat types to determine relative habitat preferences among them. The equation for comparison was as follows:

$$
\begin{aligned}
P_{a b}= & \ln \left(\text { use }_{a} / \text { availability }_{a}\right) \\
& -\ln \left(\text { use }_{b} / \text { availability }_{b}\right),
\end{aligned}
$$

where $a$ and $\mathrm{b}$ represent different habitat types for comparison, and $P_{a b}$ represents a habitat preference in comparison with $b$ habitat preference. The equation implies that if $a$ habitat type is preferred over the $b$ habitat type, $P_{a b}$ will be positive and vice versa. We then ranked habitat preference among the five habitat types from 1 (highest) to 5 (lowest) based on this comparison at both scales, home range and core-use area, and assessed its statistical significance using the permutation $t$ test (1000 iterations) in $\mathrm{R}$ with the RVAideMemoire package (Hervé 2019). Sexual differences in third-order habitat composition and third-order habitat preference were also assessed. The proportion of each habitat in a given area was log-transformed for all analyses, for which we added 0.3 for all values (Bingham and Brennan 2004; Janke and Gates 2013).

Cuckoos may depict different habitat use patterns according to the time of day and activity (e.g., foraging, calling, and egg-laying) (Nakamura et al. 2005; Rothstein et al. 1984; Vogl et al. 2004; Yoo et al. 2020). Yoo et al. (2020) showed that the calling activity of the lesser cuckoo is bimodal based on the time of day: highest in the early morning (04:00-09:00) followed by evening (17:00-20:00) and lowest during midday (09:00-17:00). Therefore, we analyzed whether habitat use patterns change diurnally in association with calling activity by comparing the third-order habitat compositions of the area identified when calling was active (04:00-09:00, 17: 00-20:00) and inactive (09:00-17:00). All analyses were performed using R 3.5.0 (R Core Team 2017).

\section{Results}

\section{Habitat composition of the study area}

The size of the study area estimated based on all location data was 8777 ha, which was composed predominantly of grassland (39\%) and field (38.6\%) habitats, followed by forest (12.1\%), orchards (5.5\%), and anthropogenic habitats (4.7\%) (Fig. 2a). However, the study area was characterized by a mosaic habitat consisting of, on average, 2.54 different habitat types per hectare (Fig. 1).

\section{Habitat selection assessment at home range: second- order selection}

The median home ranges of lesser cuckoos and their 1st and 3rd quantiles were 337.7 (193.3-407.1) ha for males, 194.7 (129.8-371.6) ha for females, and overall 315.6 (185.8-379.2) ha. We found no significant differences in the size of home range according to sex, number of location points, wing length, and study year (Table 1). The relative proportion of each habitat type in the overall home range of the lesser cuckoo was similar to that of the study area. Field and grassland types explained almost $80 \%$ of the habitat types used (Fig. 2). However, they tended to preferentially use field habitats and underutilized anthropogenic habitats in their home range, leading to a significant difference between used and available habitat proportions (one-way MANOVA: 

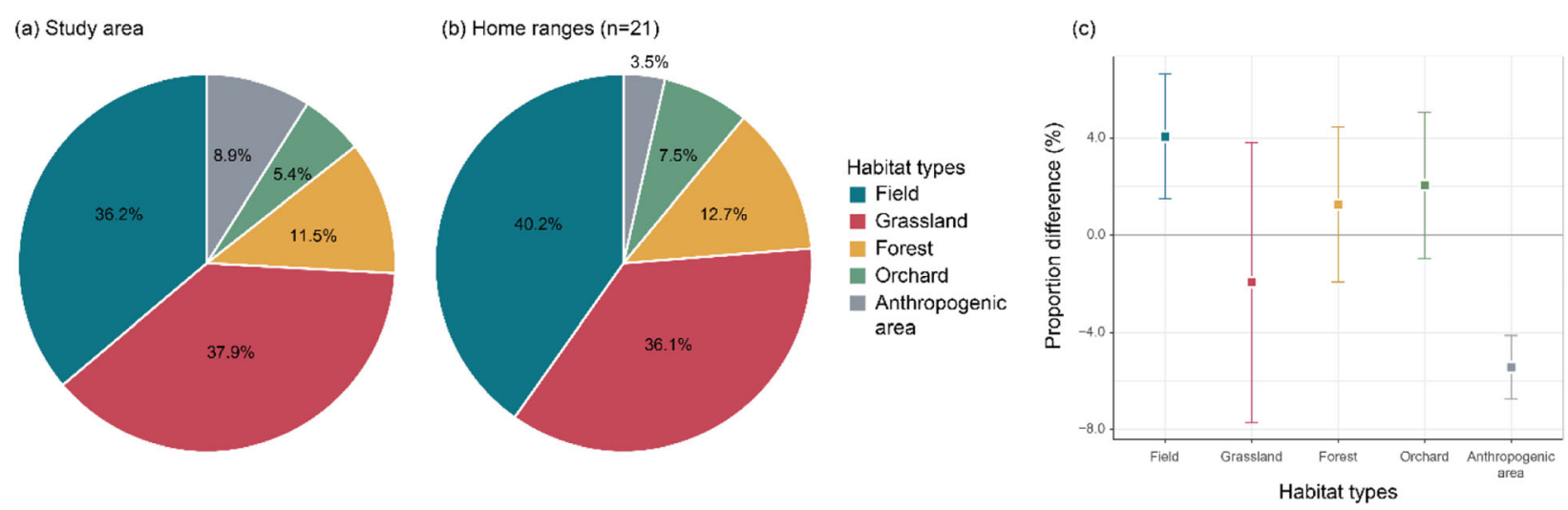

Fig. 2 Habitat composition of the study area (a) and home ranges of 21 lesser cuckoos averaged (b) and its proportional difference (c). Proportion differences in each habitat type were presented by a mean difference (square dot) with its $95 \%$ confidence intervals. Confidence intervals not crossing zero represent statistically significant differences $(p<0.05)$

$\Lambda=0.13, X^{2}{ }_{5}=77.8, P<0.001$, Fig. 2). Thus, the most used habitat in the home range of lesser cuckoos was field habitats followed by forest habitats.

\section{Habitat selection assessment in the core-use area: third- order selection}

We found a significant sexual difference in the thirdorder selection (one-way MANOVA: $\Lambda=0.81, X^{2}{ }_{5}=$ 373.78, $P<0.001$, Fig. 3 ). First, the relative proportion of habitats in the core-use area differed between sexes. Females tended to use larger proportions of grassland and forest and a smaller proportion of field habitats in their core-use area when compared to males. Both sexes also showed different habitat composition in their core-use area compared to their home range (one-way MANOVA: males: $\Lambda=0.52, X^{2}{ }_{5}=1806.8, P<0.001$, Fig. $3 \mathrm{a}-$ c; females: $\Lambda=0.76, X^{2}{ }_{5}=238.4, P<0.001$, Fig. $3 \mathrm{~d}-\mathrm{f}$ ). Male lesser cuckoos tended to use anthropogenic habitats more in their core-use area than their home range, and forest habitats less when their core was compared to their home range (Fig. 3c). In female lesser cuckoos, however, the proportions of utilized grassland and forest habitats were larger than those available in their home range, whereas the proportion of utilized field habitat was smaller than available in their home range. (Fig. 3f).

Table 1 The effect of various factors on home range size of lesser cuckoos breeding in Jeju Island, Korea

\begin{tabular}{lllll}
\hline Variable & Estimate & 95\% confidence interval & $t$ & $P$ \\
\hline Location & -0.0003 & -0.003 to 0.003 & -0.2 & 0.85 \\
Sex & 0.1719 & -0.143 to 0.487 & 1.15 & 0.27 \\
Wing & -0.0481 & -0.109 to 0.004 & -1.95 & 0.07 \\
Year & 0.2417 & -0.067 to 0.551 & 1.64 & 0.12 \\
\hline
\end{tabular}

\section{Diurnal changes in habitat selection}

We found that lesser cuckoos showed no habitat differences with regard to diurnal activity. Both habitat compositions in active period areas (males: Fig. 4a; females: Fig. 4d) and those in inactive period areas (males: Fig. 4b; females: Fig. 4e) were similar to each other in both sexes (one-way MANOVA: in males: $\Lambda=1.0, X^{2}{ }_{5}=1.94$, $P<0.86$, Fig. 4c; in females: $\Lambda=0.98, X^{2}{ }_{5}=6.78, P=$ 0.24, Fig. 4f).

\section{Habitat preferences}

In second-order selection, lesser cuckoos most preferred field, followed by forest, grassland, orchard, and anthropogenic habitats (Table 2). In third-order selection, males preferred field followed by grassland and orchard habitats and least preferred forest and anthropogenic habitats (Table 2). In contrast, females tended to prefer grassland and forest habitats, followed by field, orchard, and anthropogenic habitats (Table 2).

\section{Discussion}

Our results showed that the study area was predominantly characterized by field and grassland habitat types, which occupied almost $80 \%$ of the study area. Naturally, these two habitats types occupied most of the home range of lesser cuckoos. However, this habitat was heterogeneous rather than uniform, with on average 2.54 different habitat types occurring per hectare. This seems to be the reason why there was no diurnal change in the pattern of habitat use. Whether the habitat is heterogeneous or homogeneous plays an important role in determining home range size in avian brood parasites, as the optimal area for parasitizing may not necessarily be optimal for foraging (Nakamura and Miyazawa 1997; Rothstein et al. 1984; Vogl et al. 2002). Many populations of brown-headed 


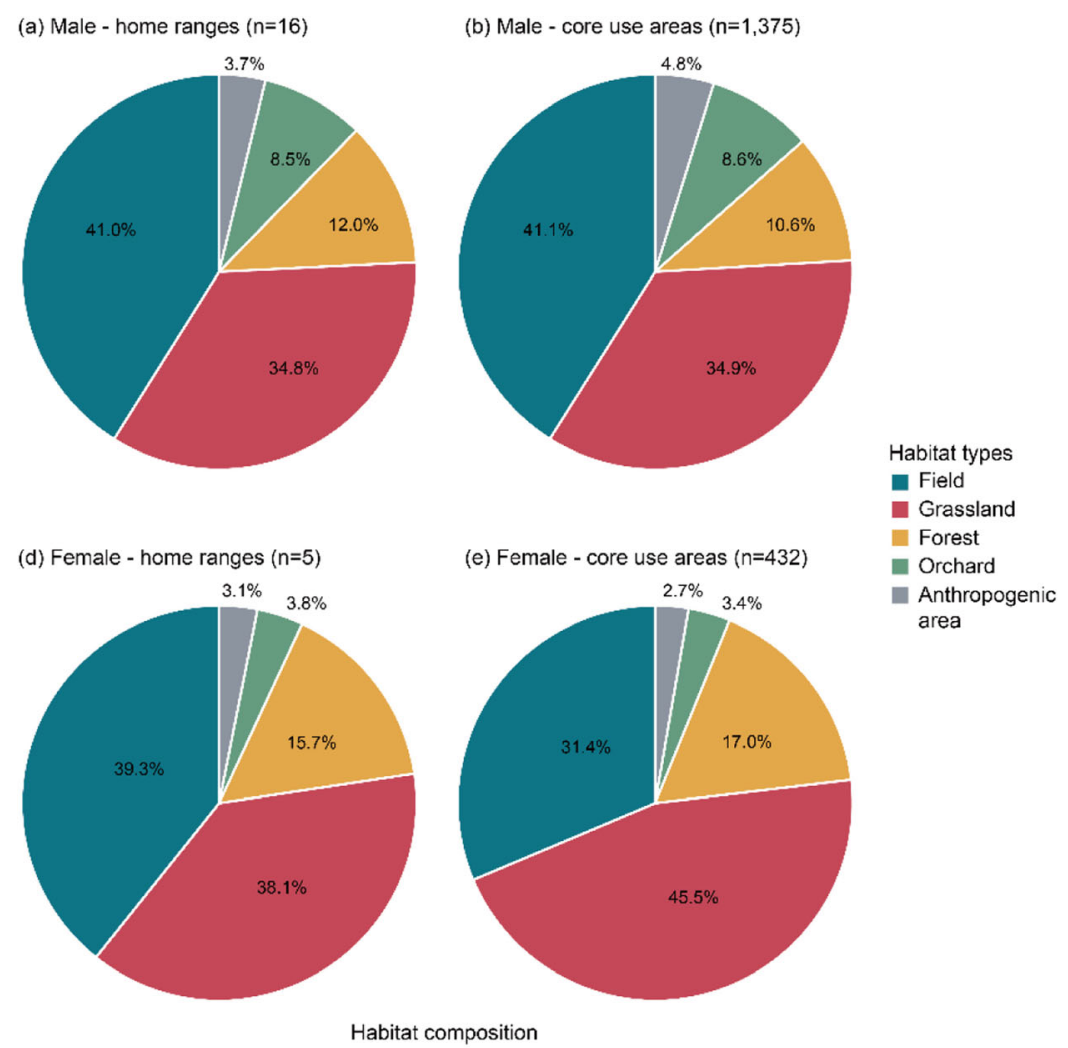

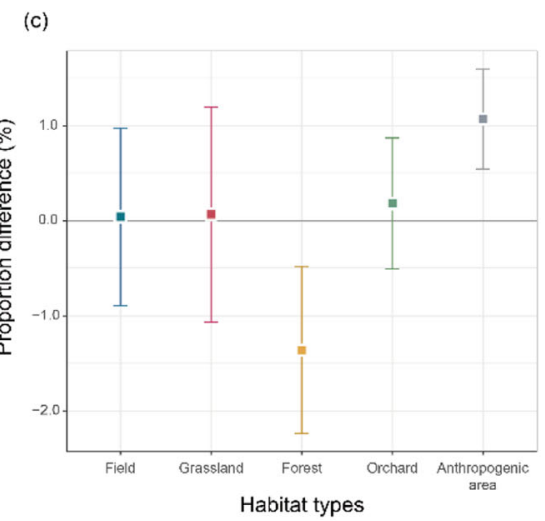

(f)

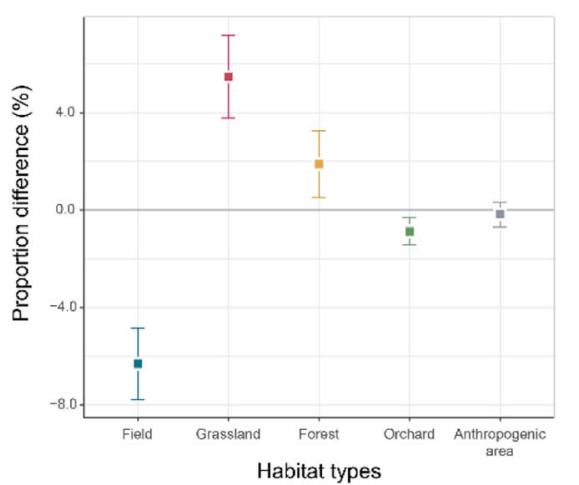

Fig 3 The comparison of habitat composition between home ranges and core use areas in male (a-c) and female (d-f) lesser cuckoos. Proportion differences $(\mathbf{c}, \mathbf{f})$ in each habitat type were presented by a mean difference (square dot) with its $95 \%$ confidence intervals. Confidence intervals not crossing zero represent statistically significant differences $(p<0.05)$

cowbirds (Molothrus ater) and common cuckoos (Cuculus canorus) commute daily between breeding and foraging sites, expanding the overall size of home ranges in these birds (approximately 1025 ha for the brown-headed cowbird, Rothstein et al. 1984; 677 ha for the common cuckoo, Nakamura and Miyazawa 1997). However, a previous study has reported that the lesser cuckoo on Jeju Island display no commuting behavior, which is presumably due to the high degree of habitat heterogeneity (Yun et al. 2019). Nevertheless, the size of their home ranges (315 ha) was relatively large when compared to those of other brood parasites that do not commute, such as shiny cowbirds (Molothrus bonariensis), screaming cowbirds (Molothrus rufoaxillaris), and Horsfield's bronze cuckoo (Chalcites basalis), which range from 27 to 170 ha (Langmore et al. 2007; Scardamaglia and Reboreda 2014). In general, territoriality, in response to increasing population density, may cause shrinkage in individual home ranges (Jirotkul 1999; Rothstein et al. 1984). However, our previous study showed that the lesser cuckoo on Jeju Island share home ranges without antagonistic territorial interactions, which may allow them to extend their home ranges (Yun et al. 2019). Further studies focusing on the factors affecting home range size will be worthwhile.

Despite overall similarities, it was recognized that the lesser cuckoo showed non-random habitat preference in second-order selection (study area $v s$. home range), with cuckoos expressing preferences primarily for field habitats, where they may obtain critical resources for breeding and foraging, while avoiding anthropogenic habitats. Third-order selection (home range vs. core-use area) also showed non-random habitat selection; however, preferences differed between sexes. In males, forest habitats appeared to be underused, whereas females tended to prefer forest and grassland habitats. Such differences in habitat use may result in spatial segregation between sexes (Bon and Campan 1996; Darden and Croft 2008; Martin and da Silva 2004). In fact, our observation of positions, during radio-tracking, showed that females were often located in the forest, whereas males were infrequently located in forests.

Sexual differences in habitat use patterns could be explained in several ways. First, sex role differences in breeding may generate different habitat preferences 


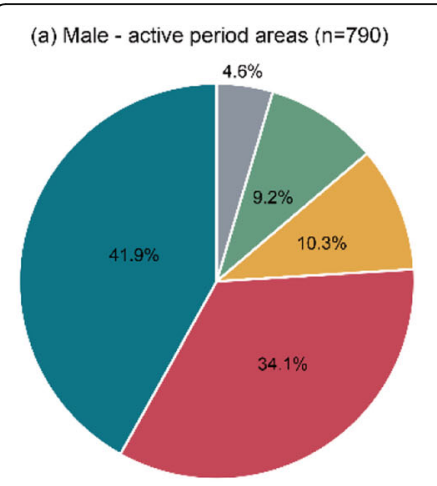

(b) Male - inactive period areas $(n=585)$

(d) Female - active period areas $(n=246)$

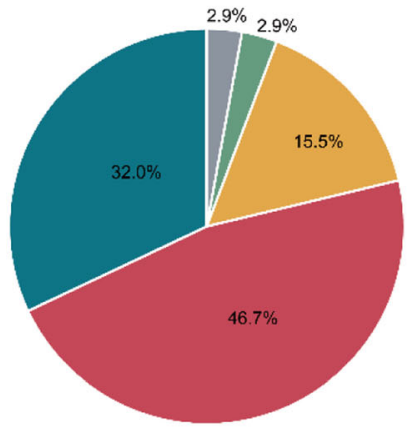

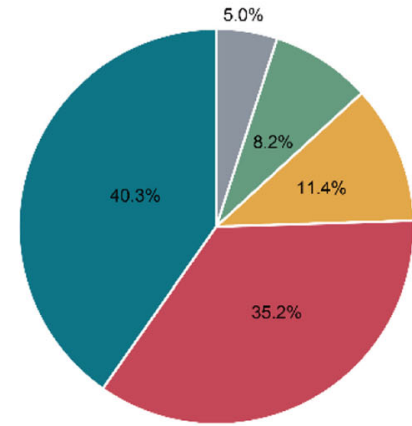

(e) Female - inactive period areas $(n=186)$

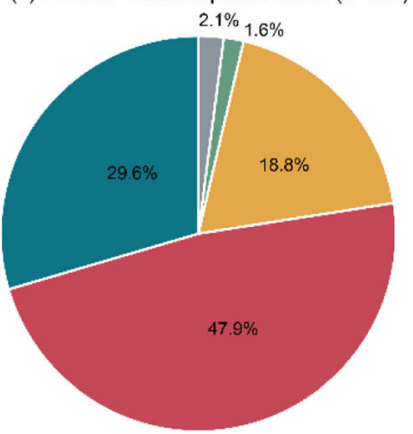

(c)

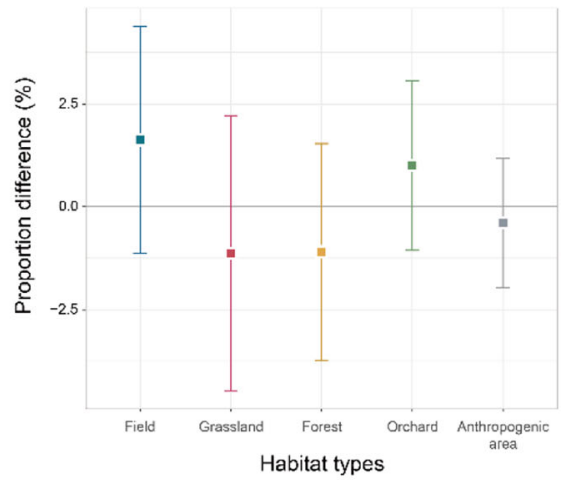

(f)

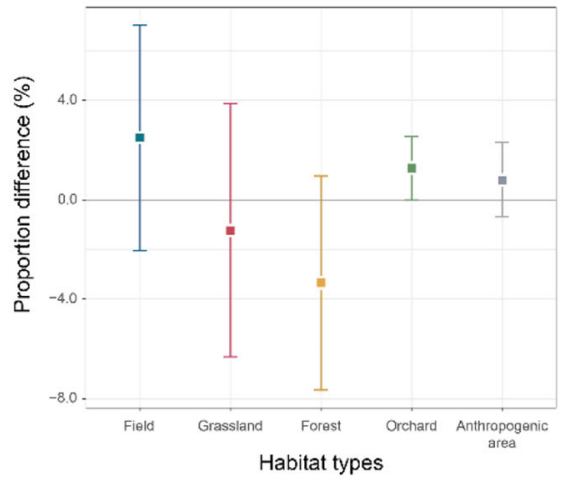

Fig. 4 The diurnal comparison of habitat composition according to activity in male (a-c) and female (d-f) lesser cuckoos. Proportion differences (c, $\mathbf{f}$ ) in each habitat type were presented by a mean difference (square dot) with its $95 \%$ confidence intervals. Confidence intervals not crossing zero represent statistically significant differences $(p<0.05)$

(Jakimchuk et al. 1987; Ornat and Greenberg 1990; Roelke and Sogard 1993). Females, but not males, are expected to search for and monitor host nests in order to approach and secretively parasitize hosts (Hauber and Dearborn 2003; Nakamura et al. 2005). Because host nest sites, such as bamboo shrubs, are often distributed along the forest edge, perches in forest areas may represent ideal locations to search for and discreetly monitor host nests. Second, different energy demands may alter habitat preferences between sexes (Chapman et al. 2003; Jakimchuk et al. 1987; Ward 1996). Females need extra food to form eggs and their major food source, hairy caterpillars, are more abundant in forests, which are characterized by the presence of more woody plants than in other habitat types (Ishizawa and Chiba 1966). Therefore, females may spend more time in forest than males, to forage. Nakamura and Miyazawa (1997) also reported that forests are a primary area for foraging in the common cuckoo. Third, sexual conflicts may cause spatial segregation in the lesser cuckoo (Hauber and Dearborn 2003; Lee et al. 2019). It is often observed that several male cuckoos chase one female excessively to attempt to copulate with her. In avian brood parasites, which do not provide parental care, females are expected to locate host nests within which to lay as many eggs as possible to maximize their fitness; in contrast, males can maximize their fitness by increasing their mating frequency (Bon and Campan 1996; Darden and Croft 2008; Hauber and Dearborn 2003; Martin and da Silva 2004; Trivers 1972). This fundamental difference in reproduction generates conflict over the optimal number of mating events between sexes, often causing sexual harassment by males. Recently, Lee et al. (2019) suggested that female cuckoos may be discreet, not only to avoid the host's attention, but also to escape excessive sexual contact by males. A dense forest with limited visibility may allow females to escape excessive male harassment as well as to forage.

\section{Conclusion}

In summary, our study showed that the home range of lesser cuckoos on Jeju Island is composed of a mosaic habitat that may result in no diurnal change in habitat use pattern and a lack of commuting behavior. Overall, 
Table 2 Ranking matrix for the second-order and third-order selection of lesser cuckoos using pairwise preference comparisons

\begin{tabular}{|c|c|c|c|c|c|c|c|}
\hline \multirow[b]{2}{*}{ Selection scale } & \multirow[b]{2}{*}{ Habitats } & \multicolumn{6}{|c|}{ Habitats } \\
\hline & & Field & Grassland & Forest & Orchard & AA & Rank \\
\hline \multirow[t]{5}{*}{ Second-order } & Field & & 0.21 & 0.16 & 0.3 & 1.37 & 1 \\
\hline & Grassland & & & -0.05 & 1.09 & 1.16 & 3 \\
\hline & Forest & & & & 0.14 & 1.21 & 2 \\
\hline & Orchard & & & & & 1.07 & 4 \\
\hline & AA & & & & & & 5 \\
\hline \multirow[t]{5}{*}{ Third-order (males) } & Field & & 0.02 & 1.09 & 0.9 & 1.05 & 1 \\
\hline & Grassland & & & 1.07 & 0.88 & 1.03 & 2 \\
\hline & Forest & & & & -0.19 & -0.04 & 5 \\
\hline & Orchard & & & & & 0.15 & 3 \\
\hline & AA & & & & & & 4 \\
\hline \multirow[t]{5}{*}{ Third-order (females) } & Field & & -0.61 & -0.004 & 0.45 & 0.81 & 3 \\
\hline & Grassland & & & 0.61 & 1.07 & 1.42 & 1 \\
\hline & Forest & & & & 0.46 & 0.81 & 2 \\
\hline & Orchard & & & & & 0.36 & 4 \\
\hline & AA & & & & & & 5 \\
\hline
\end{tabular}

Each value represents the difference in habitat preference calculated by the equation: $P_{a b}=\ln \left(\right.$ use $_{\text {row }} /$ availability $_{\text {row }}$ ) - In(use column $_{\text {availability }}$ column . Thus, the positive values indicate that the row habitat type is preferred over the column habitat type, and vice versa. Statistically significant differences ( $p<0.05)$ are in bold. The rightmost column represents resultant habitat preference ranks, which are determined by counting positive habitat preference values with other compared habitat types

$A A$ anthropogenic area

lesser cuckoos preferred field habitats in second-order selection. We identified sexual differences in third-order selection: with males preferring open spaces such as field and grassland habitats, whereas females preferred grassland and forest habitats. These results may suggest that female lesser cuckoo may use habitat not only to secure hosts, mates, and food, which are critical for their reproduction and survival, but also use habitat choice to escape unwanted risks such as male harassment and host attention.

\section{Abbreviations}

MANOVA: Multivariate analysis of variance; MCP: Minimum convex polygon

\section{Acknowledgements}

We thank Hee-Jin Noh, Kyung-Hoe Kim, Ha-Na Yoo, Hae-Ni Kim, Sohyeon Yoo, Jung-Woon Jang, Ki-Tae Ahn, and Young-Jun Kim for their assistance in the fieldwork. We are also grateful to Yong-Ho Park and Sung-Hee Shim for their warm hospitality during fieldwork.

\section{Authors' contributions}

SY and JWL designed the study. SY and JWL collected and analyzed data and wrote the manuscript. All authors read and approved the final manuscript.

\section{Funding}

This study was supported by Basic Science Research Program through the National Research Foundation of Korea (NRF) funded by the Ministry of Education (grant number: NRF-2012R1A6A3A04040003,

2017R1D1A1B03030329), for which we are most grateful.

\section{Availability of data and materials}

The datasets used and/or analyzed during the current study are available from the corresponding author (Dr. Jin-Won Lee, jwlee99@khu.ac.kr) on reasonable request.

\section{Ethics approval and consent to participate}

Lesser cuckoos were captured with permits by the local governments and the cultural heritage administrations of Korea, and the fieldwork procedures conformed to the national law of Korea and the guidelines of the Kyung Hee University Animal Ethics Committee.

\section{Consent for publication}

Not applicable.

\section{Competing interests}

The authors declare that they have no competing interests.

Received: 9 March 2020 Accepted: 15 June 2020

Published online: 26 June 2020

\section{References}

Aebischer NJ, Robertson PA, Kenward RE. Compositional analysis of habitat use from animal radio-tracking data. Ecology. 1993;74:1313-25.

Bingham RL, Brennan LA. Comparison of type I error rates for statistical analyses of resource selection. J Wildl Manag. 2004;68:206-12.

Bon R, Campan R. Unexplained sexual segregation in polygamous ungulates: a defense of an ontogenetic approach. Behav Process. 1996;38:131-54.

Bozek CK, Prange S, Gehrt SD. The influence of anthropogenic resources on multi-scale habitat selection by raccoons. Urban Ecosyst. 2007;10:413-25.

Brown JS. Patch use as an indicator of habitat preference, predation risk, and competition. Behav Ecol Sociobiol. 1988;22:37-47.

Chapman T, Arnqvist G, Bangham J, Rowe L. Sexual conflict. Trends Ecol Evol. 2003;18:41-7.

Cody ML. Habitat selection in birds. Califonia: Academic Press; 1985.

Crawley MJ. The R book. West Sussex: John Wiley \& Sons; 2012.

Croston R, Hauber ME. The ecology of avian brood parasitism. Nat Educ Knowledge. 2010;1:3. 
Darden SK, Croft DP. Male harassment drives females to alter habitat use and leads to segregation of the sexes. Biol Lett. 2008;4:449-51.

Dickson BG, Beier P. Home-range and habitat selection by adult cougars in southern California. J Wildl Manag. 2002;66:1235-45.

Ersts PJ, Rosenbaum HC. Habitat preference reflects social organization of humpback whales (Megaptera novaeangliae) on a wintering ground. J Zool. 2003;260:337-45.

Freeman S, Jackson WM. Univariate metrics are not adequate to measure avian body size. Auk. 1990;107:69-74.

Godet L, Marquet M, Eybert M-C, Grégoire E, Monnet S, Fournier J. Bluethroats Luscinia svecica namnetum offset landscape constraints by expanding their home range. J Ornithol. 2015;156:591-600.

Hamao S. Japanese Bush Warbler. Bird Res News. 2014;4:3-4

Hamao S, Hayama M. Breeding ecology of the Japanese Bush Warbler in the Ogasawara Islands. Ornithol Sci. 2015:14:111-5.

Hauber ME, Dearborn DC. Parentage without parental care: what to look for in genetic studies of obligate brood-parasitic mating systems. Auk. 2003;120:1-13.

Hervé M. RVAideMemoire: testing and plotting procedures for biostatistics. R package version 0.9-73. 2019. https://CRAN.R-project.org/package= RVAideMemoire. Accessed 23 Dec 2019.

Ishizawa J, Chiba S. Food analysis of four species of cuckoos in Japan. J YIO. 1966; 4:302-26.

Jakimchuk RD, Ferguson SH, Sopuck LG. Differential habitat use and sexual segregation in the Central Arctic caribou herd. Can J Zool. 1987;65:534-41.

Janke AK, Gates RJ. Home range and habitat selection of northern bobwhite coveys in an agricultural landscape. J Wildl Manag. 2013;77:405-13.

Jirotkul M. Population density influences male-male competition in guppies. Anim Behav. 1999;58:1169-75.

Johnson $\mathrm{DH}$. The comparison of usage and availability measurements for evaluating resource preference. Ecology. 1980;61:65-71.

Langmore NE, Adcock GJ, Kilner RM. The spatial organization and mating system of Horsfield's bronze-cuckoos, Chalcites basalis. Anim Behav. 2007;74:403-12.

Lee J-W. Searching for hosts of avian brood parasites breeding in Korea. Korean J Ornithol. 2014:21:25-37.

Lee J-W, Kim H-N, Yoo S, Yoo J-C. Common cuckoo females may escape male sexual harassment by color polymorphism. Sci Rep. 2019;9:7515.

Martin AR, da Silva VMF. River dolphins and flooded forest: seasonal habitat use and sexual segregation of botos (Inia geoffrensis) in an extreme cetacean environment. J Zool. 2004;263:295-305.

Mohr CO. Table of equivalent populations of North American small mammals. Am Midl Nat. 1947;37:223-49.

Mysterud A. The relationship between ecological segregation and sexual body size dimorphism in large herbivores. Oecologia. 2000;124:40-54.

Nakamura H, Miyazawa Y. Movements, space use and social organization of radio-tracked common cuckoos during the breeeding season in Japan. Jpn J Ornithol. 1997;46:23-54.

Nakamura H, Miyazawa Y, Kashiwagi K. Behavior of radio-tracked common cuckoo females during the breeding season in Japan. Ornithol Sci. 2005:4:31-41.

Ornat AL, Greenberg R. Sexual segregation by habitat in migratory warblers in Quintana Roo, Mexico. Auk. 1990;107:539-43.

Payne RB. The cuckoos. New York: Oxford University Press; 2005.

Pulliam HR, Danielson BJ. Sources, sinks, and habitat selection: a landscape perspective on population dynamics. Am Nat. 1991;137:S50-66.

R Core Team. R: a language and environment for statistical computing. Vienna: $R$ Foundation for Statistical Computing; 2017.

Rettie WJ, McLoughlin PD. Overcoming radiotelemetry bias in habitat-selection studies. Can J Zool. 1999;77:1175-84.

Roelke DL, Sogard SM. Gender-based differences in habitat selection and activity level in the northern pipefish (Syngnathus fuscus). Copeia. 1993;1993:528-32.

Rothstein SI, Verner J, Steven E. Radio-tracking confirms a unique diurnal pattern of spatial occurrence in the parasitic brown-headed cowbird. Ecology. 1984; 65:77-88.

Scardamaglia RC, Reboreda JC. Ranging behavior of female and male shiny cowbirds and screaming cowbirds while searching for host nests. Auk. 2014; 131:610-8

Seaman DE, Millspaugh JJ, Kernohan BJ, Brundige GC, Raedeke KJ, Gitzen RA. Effects of sample size on kernel home range estimates. J Wildl Manag. 1999: 739-47.

Sykes PW, Carpenter JW, Holzman S, Geissler PH. Evaluation of three miniature radio transmitter attachment methods for small passerines. Wildl Soc Bull. $1990 ; 18: 41-8$
Todorov V, Filzmoser P. An object-oriented framework for robust multivariate analysis. J Stat Softw. 2009;32:1-47.

Trivers RL. Parental investment and sexual selection. In: Campbell B, editor. Sexual selection and the descent of man. Chicago: Aldine; 1972. p. 136-79.

Vogl W, Taborsky M, Taborsky B, Teuschl Y, Honza M. Cuckoo females preferentially use specific habitats when searching for host nests. Anim Behav. 2002;64:843-50.

Vogl W, Taborsky B, Taborsky M, Teuschl Y, Honza M. Habitat and space use of European cuckoo females during the egg laying period. Behaviour. 2004;141: 881-98.

Ward S. Energy expenditure of female barn swallows Hirundo rustica during egg formation. Physiol Zool. 1996;69:930-51.

Yoo S, Kim H-N, Lee J-W, Yoo J-C. Seasonal and diurnal patterns of population vocal activity in avian brood parasites. Ibis. 2020: doi:https://doi.org/10.1111/ ibi.12741.

Yun S, Kim H, Moon H-K, Lee J-W, Yoo J-C. Home range overlap and its genetic correlates in an avian brood parasite, the lesser cuckoo Cuculus poliocephalus. J Ethol. 2019;37:271-81.

\section{Publisher's Note}

Springer Nature remains neutral with regard to jurisdictional claims in published maps and institutional affiliations.
Ready to submit your research? Choose BMC and benefit from:

- fast, convenient online submission

- thorough peer review by experienced researchers in your field

- rapid publication on acceptance

- support for research data, including large and complex data types

- gold Open Access which fosters wider collaboration and increased citations

- maximum visibility for your research: over $100 \mathrm{M}$ website views per year

At $\mathrm{BMC}$, research is always in progress.

Learn more biomedcentral.com/submissions 